\title{
Using Regional-scale Pre- and Post Hurricane Katrina Lidar for Monitoring and Modeling
}

\author{
Jason Stoker, D. Phil Turnipseed and K. Van Wilson \\ United States Geological Survey \\ USA
}

\section{Introduction}

Hurricane Katrina caused the largest natural disaster in U.S. history, with the eye of the storm hitting about $55 \mathrm{~km}$ east of New Orleans (Turnipseed et al., 2007). Although the storm initially brought more destruction to areas along the Mississippi and Louisiana coast, several levees protecting New Orleans failed the following day, and the city, about $80 \%$ of which is below sea level, was flooded. The flooding in New Orleans and the hurricane storm tide that impacted the Gulf of Mexico coast in Mississippi and southeast Louisiana killed hundreds, made tens of thousands more homeless, and triggered a massive relief effort that is still ongoing (Travis, 2005). It has been estimated that Hurricane Katrina caused the loss of more than 1,800 human lives and about $\$ 81$ billion in damage (Turnipseed et al., 2007). The insured losses moved Katrina into the number one spot globally of all disasters since 1970 . Over 200 miles of the 350 miles of levees and flood walls were damaged and had to be repaired prior to the next hurricane season that started in June 2006. In addition to the many rescue and recovery efforts that were initiated immediately after the storm, there was a strong need to quickly ascertain the areas inundated by storm tide water for rescuers and assess wind and flood damage (Raber and Tullis, 2007). First responders, emergency managers, city planners, insurance companies, and other groups have critical needs for geospatial information relating to the extent and effect of Hurricane Katrina's devastation to make rapid and efficient emergency response decisions.

In the late evening of August 25, 2005, less than two hours before Tropical Storm Katrina made first landfall on the southeastern Atlantic coast of Florida, the storm was upgraded to a Category 1 (Saffir-Simpson Hurricane Scale) hurricane after forming as a tropical depression over the Bahamas on August 19 (Knabb et al., 2005). After spending only six hours over land in southern Florida, Tropical Storm Katrina reentered open water in the southeastern Gulf of Mexico in the early morning of August 26, just north of Cape Sable (Knabb et al., 2005). During the next three days, Katrina rapidly intensified from a tropical storm to a Category 5 hurricane by late in the afternoon of August 28 with a maximum peak wind speed intensity of greater than 170 miles per hour ( $\mathrm{mph}$ ). This maximum intensity occurred about 170 nautical miles southeast of the mouth of the Mississippi River and helps explain the extreme magnitude of the storm tide height that occurred when Hurricane Katrina made landfall (Knabb et al., 2005). During Katrina's maximum intensity, tropical storm and hurricane force winds extended 200 and 90 nautical miles from the eye, respectively (Knabb et al., 2005). These conditions defined Hurricane Katrina as one of the 
most intense and largest storms to ever form in the northern region of the Gulf of Mexico (Knabb et al., 2005). Katrina created the highest measured surge and equaled the highest wave height recorded on a NOAA buoy in North America (Link, 2010). After some erosion of the eye wall late on August 28, Hurricane Katrina turned northward to make landfall near Buras, Louisiana, with sustained winds of about $125 \mathrm{mph}$, making the storm a strong Category 3 hurricane. Hurricane Katrina made initial landfall on the northern Gulf of Mexico coast early on August 29, 2005, first slamming into the Mississippi River delta near Buras, Louisiana, and later, the Pearl River delta at the Louisiana-Mississippi border with an estimated intensity of $120 \mathrm{mph}$ sustained winds. Knabb et al. (2005) explained that although Hurricane Katrina had weakened from a Category 5 to a Category 3 hurricane in the last eighteen hours before landfall, the radial extent of tropical storm and hurricane force winds remained about the same, which further explains the extreme storm tide in southeastern Louisiana and the Mississippi Gulf coastal region.

Katrina weakened rapidly after its final landfall near the Louisiana-Mississippi border, becoming a Category 1 storm by 1800 UTC on August 29 in central Mississippi. The storm was downgraded to tropical storm status early on August 30, after five days as a hurricane in the Gulf of Mexico (Knabb et al., 2005).

\subsection{Katrina Storm surge}

Hurricane force winds change the water level, a process called storm surge generation. Storm surge is defined here as the abnormally high still-water levels attributable to the presence of the storm itself. That is, storm surge for the purposes of this chapter does not include the discussion of the destructive wave action that occurs on top of storm surge and usually is evident in these events. The water level during a storm is influenced by the storm surge, the timing of the storm with the astronomical tidal variations that normally occur without the presence of a storm, and the areal extent of the storm. The word "still" to describe the water level is intended here to differentiate between the slower rise and fall of the water surface due to the storm surge/astronomical tide level that occurs over time scales of hours, and changes in water surface that occur at much higher frequencies associated with water surface motion due to wave action that occur over time scales from seconds to tens of seconds.

Hurricane winds exert stress at the water surface that pushes the water. Wind effect on storm surge has a higher contribution in shallow water. The shallower the water at the landwater interface, the more effect wind can have in developing storm surge. Like waves, the storm surge generation potential for a storm is also related to the surface shear stress of the water. Broad, shallow continental shelf regions are the most effective areas for generating storm surge, and therefore most vulnerable to damage from storm surge. As winds push water, it moves freely until it encounters a coastal land mass or other obstruction where it then begins to amass. Indentations, irregularities, and pockets along the U.S. coast are particularly prone to catching water pushed toward and in to these geographic features by the wind. The Mississippi River delta is a coastal land feature that acts to catch water being pushed toward it along the Mississippi and Alabama continental shelves. Since winds in hurricanes rotate in counterclockwise direction, hurricanes in the northern Gulf of Mexico tend to create winds that blow from the east in the northern gulf.

In the case of Hurricane Katrina, these winds from the east acted to push water toward Southeast Louisiana, and toward the Mississippi River delta. As storm surge grew and 
inundated the wetlands of Southeast Louisiana, the Mississippi River levees in the lower basin became a topographic control. Along the Southeast Louisiana coast, for Katrina, the storm surge contribution due to wind and geographic/topographic controls exceeded $15 \mathrm{ft}$ in places, and along the Mississippi coast it exceeded $20 \mathrm{ft}$ in places (IPET, 2008). This contribution of the water level can vary greatly with location.

Precipitation can increase the storm-induced water level, either by falling directly on the local water bodies, or by falling on the adjacent watershed and then running off into the water bodies. The effect of direct precipitation can be significant to the peak storm surge. Typically, some of the direct precipitation will be felt after the storm surge peak is experienced; and often the effect of runoff from the adjacent watershed will be experienced after the peak storm water level has been experienced.

One of the primary efforts in determining the physical performance of flood control structures in the area in and around New Orleans after the Hurricane Katrina disaster was the Interagency Performance Evaluation Task Force (IPET). A principal objective of the IPET was to determine the effects of Hurricane Katrina on flow control structures and to provide a framework for the subsequent repair and rebuilding of hurricane protection in New Orleans. The IPET was made up of experts from 25 universities, 25 private companies and 10 government agencies (Link, 2010). The IPET study used a combination of measured data and model-simulated data to characterize water level conditions over time. Measured data fell into two categories: High Water Mark (HWM) measurements which capture peak water levels, and hydrographs, which capture the water level as a function of time (IPET, 2008). An extensive post-storm effort was undertaken to identify and survey HWMs following passage of the storm. While HWMs can capture the peak water levels, they do not record the temporal variability in the water level and generally do not include wave action. HWMs also have their own inherent quality issues, such as whether they reflect a peak condition, and whether or not water surface motion due to wind-caused waves is reflected in a HWM. Measured hydrographs are a reliable source of data for capturing both the temporal variation and the maximum water level. Water level fluctuations were measured with instrumentation during the build-up stage of the storm at a number of sites throughout the study region; however, few instruments operated throughout the storm. Most of them failed prior to the peak. Consequently, there are little continuously measured data that capture peak conditions. In a few cases, photographs and other visual observations were utilized to provide information about the temporal variation of water level to supplement the recorded hydrographs. These constructed hydrographs proved to be extremely valuable for characterizing conditions along the south shore of Lake Pontchartrain.

\subsection{Lidar}

After Hurricane Katrina, the USGS quickly began the task of obtaining and processing detailed existing pre-Katrina Light Detection and Ranging (lidar) data throughout the affected region. Farris et al. (2007) documented many technologies used in the USGS response to the devastation caused by Katrina, including lidar mapping of New Orleans. Lidar mapping is an effective and accurate technology for producing high-resolution elevation data for bare earth, vegetation, and structures (Lefsky et al. 2002; Stoker et al., 2006). High level spatial detail and vertical accuracy of elevation measurements make lidar remote sensing an excellent mapping technology for use in low-relief hurricane-prone coastal areas (Farris et al., 2007; Gesch, 2009). By converting lidar data into usable 
information, extremely accurate, high-resolution models can be used to visualize and quantitatively represent scenes in three dimensions.

In addition to high-resolution bare earth digital elevation models (DEMs) used in this effort, other lidar-derived products possible include quantitative estimates of vegetative features, such as canopy height, canopy closure, and biomass (Lefsky et al., 2002), and models of urban areas such as building footprints and three-dimensional city models (Maas, 2001). However, due to the fact that the topographic lidar laser is usually in the near-infrared wavelength (around $1064 \mathrm{~nm}$ ), bare ground topography accuracy can be poor if flooding of stream channels and floodplains occurs during lidar acquisition.

Due to the sheer size of Hurricane Katrina, an unprecedented regional analysis at very high resolution and accuracy was needed to properly quantify and understand the effects of the hurricane and the entire storm tide. Many disparate sources of lidar data were acquired and processed for varying environmental reasons by pre- and post- Katrina projects (Stockdon et al., 2009). Lidar data from disparate sources were available for Baldwin and Mobile Counties in Alabama, for Jackson, Hancock, and Harrison Counties in Mississippi, and for the southeastern parishes affected by the storm in Louisiana. These separate datasets encompassed the most significantly affected areas from Hurricane Katrina. These datasets were in several formats and projections and originally obtained by the USGS in varying phases of completion. As a result the task of producing a seamless digital elevation dataset required a high level of coordination, research, and revision. To create a seamless digital elevation dataset, many technical issues had to be resolved before producing the desired 1/9-arc-second ( 3 meter) grid needed as the map base for projecting the Katrina peak storm tide in the affected coastal region. As a result of these complex datasets, a methodology was developed to construct seamless DEMs from multipurpose, multiuse, and disparate lidar datasets that serves as a template for use by other agencies. The output of this work included an easily accessible Web application for viewing the maximum storm tide caused by Hurricane Katrina in southeastern Louisiana, Mississippi, and Alabama (Stoker et al., 2009).

\section{Methods}

\subsection{High water Mark analyses}

The passage of hurricanes often results in short-period wind waves on top of the much longer-period storm surge that couple to create various types of debris lines including vegetation, seeds, dirt, man-made trash, and dislodged building material. These debris lines can be deposited on or adhere to some surfaces after the peak water level has been reached and it begins to fall. The deposited debris typically leaves a linear feature that is referred to as a High Water Mark (HWM) and this mark with experience and interpretation can be used to approximate the local peak water level. The highest quality marks for estimating storm still-water levels are those that have little or no wave effect. Some HWMs are collected where significant wave or backwater effects are present, but those effects should be noted in the field surveying notes and documentation. In this analysis, the focus was on use of HWMs as indicators of storm water level, without the effects of water level fluctuations due to wave crests wave effects, or riverine flooding.

The U.S. Geological Survey (USGS) began flagging and surveying HWMs along the Mississippi coast on September 1, 2005 to compare the peak surge to the peak surge of Hurricane Camille in 1969. An extensive post-storm effort was undertaken to identify and survey HWMs following passage of the storm in concert with the IPET. While certain 
HWMs captured the peak water levels well, they did not contain information about the temporal variation of water level. It is critical in the analysis of HWMs to determine if the HWM reflects the maximum crest of the storm. An experienced field hydrologist /hydrographer can usually determine if the HWM has been affected by waves, riverine flooding or other factors.

Acquisition of HWMs following Katrina was principally performed by three federal agencies: USGS, the U.S. Army Corps of Engineers (USACE), and the Federal Emergency Management Agency (FEMA) (or a FEMA contractor). The State of Louisiana through the Louisiana State University (LSU) also helped recover HWM data. All entities participating in the IPET shared the data. Marks identified by USACE, FEMA, and LSU were also recovered by that respective agency. Most of the marks identified by USGS were recovered by FEMA (or a FEMA contractor). A subset of approximately 50 marks was also recovered by USGS field crews to confirm elevations provided by FEMA contractors. All HWMs were reviewed and assigned a reliability rating. The reliability of each HWM was assessed as "Excellent," "Good," "Fair/Poor," or "Unknown" if there was no information provided regarding the type of mark or setting in which it was acquired. Currently, there is not a standard method for determining HWM reliability. Moreover, assignment of reliability values to HWMs is not a totally objective process, but by its nature involves both objective and subjective elements. HWM recovery and determination requires experience and engineering judgment. Discussion by the IPET assigning the reliability values led to a consensus that the mark should reflect, as closely as possible, the stable ("still") or mean, storm water level. That is, the physical setting where the mark was located should approximate a tide gauge stilling-well if possible. The basis for this consensus is that storm surge models do not explicitly include wave crest or other wave effects, and one of the important uses of the HWM data is validation and verification of surge model simulations.

\subsection{Lidar processing}

The USGS and its partners began acquiring, organizing, and preprocessing lidar datasets immediately following the landfall of Hurricane Katrina. Lidar data were obtained from multiple sources, including private, local and state agencies, and Federal bureaus, such as the National Oceanic and Atmospheric Administration (NOAA), the USGS, and the USACE. Many disparate sources of lidar data were acquired and processed for individual projects to accomplish various tasks pre- and post-Katrina. The original datasets were in several different formats and projections and were processed to varying phases of completion before they were acquired for this project (Table 1). Some of these datasets already existed in a bare earth, ready-to-use format, and were easily downloadable from the USGS National Elevation Dataset (NED) (Gesch et al., 2002). Some of the raw point cloud data were already available and being processed for the USGS Center for Lidar Information Coordination and

\begin{tabular}{|c|c|c|c|c|}
\hline Area & Format & Projection & Elevation Units & Metadata? \\
\hline Eastem Louistana Panshes & S.m DEM (raster) & UTM & Feet & Yes \\
\hline Hancock County, MS & LAS binary (points): Reprocessed with breaklipes added & MS State Plane (meters) & Feet & Yes \\
\hline Hamison County. MS & ASCII XYZ (points) \& EBN bianry: Reprocessed with breaktines added & MS State Plane (teet) & Meters & No \\
\hline Jackson County, MS & LAS binary (points): Reprocessed with breaklines added & MS State Plane (meters) & Feet & Yes \\
\hline Mobile County, AL & LAS binary (points) w/ CAD breaklines & AL State Plane (feet) & Feet & Partial \\
\hline Baldwin County, AL & ESRI Shapefiles: Mass points and breaklines & Al Stare Plane (feet) & Meters & Partial \\
\hline
\end{tabular}

Table 1. Dataset differences (from Stoker et al., 2009) 
Knowledge (CLICK) database (Stoker et al., 2006). The lidar data were in various file formats and projections and represented different levels of processing. Differences in datum, projection, units, and file types created a need to standardize the inputs in order to create a regional product. The end product was a raster in a geographic coordinate system, which is the standard deliverable format for the NED.

\section{Southeastern Louisiana Datasets}

Lidar data that were already bare-earth processed and gridded into an acceptable Digital Elevation Model (DEM) format were available from southeastern Louisiana parishes. The Louisiana data were projected in Universal Transverse Mercator (UTM) Zone 15-NorthMeters, North American Datum of 1983 (NAD 83). The original source DEM resolution was $5 \mathrm{~m} \times 5 \mathrm{~m}$, and the data were resampled to 1/9-arc-second grids to be consistent in resolution (3 meters) with the other datasets. Although the datasets were resampled to a 3-m resolution, the data were originally acquired and processed at a 5-m resolution.

\section{Mississippi Gulf Coast Datasets}

A seamless dataset for the three counties that border the Gulf of Mexico in Mississippi (i.e., Hancock, Harrison, and Jackson Counties) was created by processing lidar data of each county separately and then merging them.. The Hancock and Jackson County lidar data were flown on February 25th and March 1, 10, 11 and 12th 2005 . The sensor pulse rate was set at $29 \mathrm{kHz}$ with a field of view of 45 degrees. The aircraft was flown at an altitude of 12,000 feet, and the point spacing was approximately 5 meters. The data were delivered as binary laser file format (LAS) files in State Plane Meters Mississippi East NAD 83, with elevation data (z-values) in feet. Initially, these LAS files were preprocessed and point data were classified as bare or non-bare. Because of the large size of the LAS files, the data were tiled to more efficiently manage the processing. Each tile was interpolated to a raster format to convert the data from points to 1/9-arc-second grids.

The Harrison County lidar data were flown on March 8-9th, 2004. They were obtained at an altitude of 11,100 feet above mean terrain. The sensor pulse rate was set at $20 \mathrm{kHz}$ with a field of view of 45 degrees. Average swath width of the raw data was 9,112 feet, and the point spacing was approximately 5 meters. The final data were delivered as bare earth ASCII comma-delimited text files, as well as proprietary files. These data were projected in State Plane Feet Mississippi East feet NAD 83, although the z-values were in meters and not feet. These data were converted to feet for compliance with vertical units in the Jackson and Hancock Counties' datasets before being preprocessed, tiled, and interpolated into 1/9-arcsecond grids. These data were processed using software to process the data to surfaces, and then were converted into 1/9-arcsecond grids.

\section{Alabama Datasets}

Both coastal Alabama counties (Baldwin and Mobile) were significantly affected by the Hurricane Katrina storm tide. The Mobile County, Alabama lidar data obtained by the USGS were LAS binary files with breaklines as computer-aided drafting files. A breakline is a hard-edge digitized line that is delineated to have a constant defined elevation. The data were in State Plane Feet Alabama West NAD83 with z-values in feet. The files were processed to create surfaces with breaklines, and then output into grid formats for conversion into ArcGIS compliant grids. The Baldwin County, Alabama lidar data were acquired as mass points and breaklines using ArcGIS shapefile format. These data were projected in State Plane Feet Alabama West NAD83 with z-values in feet. The data were 
converted to Triangulated Irregular Networks (TINs), and breaklines were added before they could be converted to grids.

After the Mississippi data were completely processed once, the lidar points were completely reprocessed to add in breakline information. Each binary dataset was converted to an ArcGIS shapefile, and then converted to TINs. The breakline data were then incorporated into the TINs, and the files were converted to 1/9-arc-second raster grids. In all, 182 gigabytes (GB) of lidar data were processed for five counties in Mississippi and Alabama. The datasets for Mississippi and Louisiana were seamlessly integrated using ASSEMBLE, a custom program used for processing the NED (Gesch et al., 2002). All datasets were projected into a geographic coordinate system for use in the ASSEMBLE program. The ASSEMBLE program mitigated all noticeable dataset seams and other edge boundary anomalies (Stoker et al., 2009). The final output was a seamless digital elevation model of the region at a resolution of 3 meters available for viewing on the web.

\subsection{Storm surge analyses}

Mapped storm surge data are critical for emergency managers and decision makers of affected coastal communities and other areas, but also provide future design criteria for engineers and planners in the rebuilding phase after a coastal zone is devastated by a storm. Historically these data have been relatively scarce. Following the Hurricane Katrina disaster, high-resolution digital elevation data, HWMs, and mapping interpolation methods were used to estimate storm tide throughout the Katrina affected region in Louisiana, Mississippi and Alabama. Turnipseed et al. (2007) used a spline interpolation method along with interpretative analysis to complete a thorough storm surge analysis. The maximum Hurricane Katrina storm tide was digitally mapped, using water-level data collected by the USGS, FEMA, USACE, and others.

Maps are inherently in error, however, and the error varies with the scale and resolution of the map created. High-resolution digital maps generated for the Katrina storm tide also have error, and in places, ignore the effects of topography, roads, and other hydraulic features that resist inland flowing storm tide. This analysis is also subject to erroneous extrapolations beyond the data locations. Simply interpolating a surface from the data may not result in reliable maps of storm tide, but clearly the data provide engineers, planners, and emergency officials with a tool to prepare, warn, and respond to coastal disasters such as Hurricane Katrina.

Many published interpolation methods permit depictions of storm tide inundation, but often ignore the effects of topographic and hydraulic features that influence the relative depths and extent of storm tide inundation. These storm tide analyses were used to create an improved digital map coverage of the maximum storm tide produced by Hurricane Katrina and to compare the improved map to a flood-inundation map prepared by FEMA. Storm surge analysis and the creation of storm-tide maps involve iterative steps of interpretation, refinement, extrapolation, and often further interpretation and refinement of the algorithm-derived coverages. Automated feature extraction and even generalized interpolation methods without the experienced and trained eye of the scientist cannot accurately evaluate mapping features, especially in regions of low topographic relief such as found in the north Gulf of Mexico coast. Figure 1 depicts the maximum storm-tide elevation of the Katrina storm and is a digital coverage created by using hundreds of HWMs, interpretation, a high-resolution digital elevation model created from LiDAR data and a 
spline interpolation of topographic and hydraulic influences from the storm tide. Berenbrock et al. (2009) used a barrier mapping technique to effectively map the Hurricane Rita storm tide in Louisiana and Texas from over 30 continuously recording storm tide pressure transducers.

Identification and insertion of barriers to simulate natural features such as islands, elevated highways and railroads, dunes and bluffs, natural levees, canal berms and other features significantly affect how inland flow from storm tides inundates the landscape. A general description of a typical step-wise analysis to insert flow barriers into a high-resolution minimally included:

- Assembly of a storm-surge HWMs or other method to simulate the maximum extent of flooding; For the Hurricane Katrina storm surge coverage, over 1500 HWMs were analyzed, of which over $800 \mathrm{HWMs}$ were used to prepare the coverage.

- Creation of a first-cut digital storm-tide elevation surface using the spline method or other method (Berenborck et al., 2009; Turnipseed et al., 2007).

- Interpretation and analysis of the storm-tide elevation surface to create an estimation of the extent of flooding from the storm-tide inundated area (boundary of flooding) from the interpolated data. This should also include an identification of zero elevation contour;

- Identification and digitization of natural hydraulic barriers from topographical maps or other data that serve as natural impedance of storm tide inundation on the landscape. These might include islands, large bridge structures, elevated highways and railroads, dunes and bluffs, natural levees, canal berms, and any other feature that could significantly affect the flow of storm-tide inland;

- Creation of a maximum storm-surge map utilizing all HWM data or other data used to represent storm tide elevation across the landscape

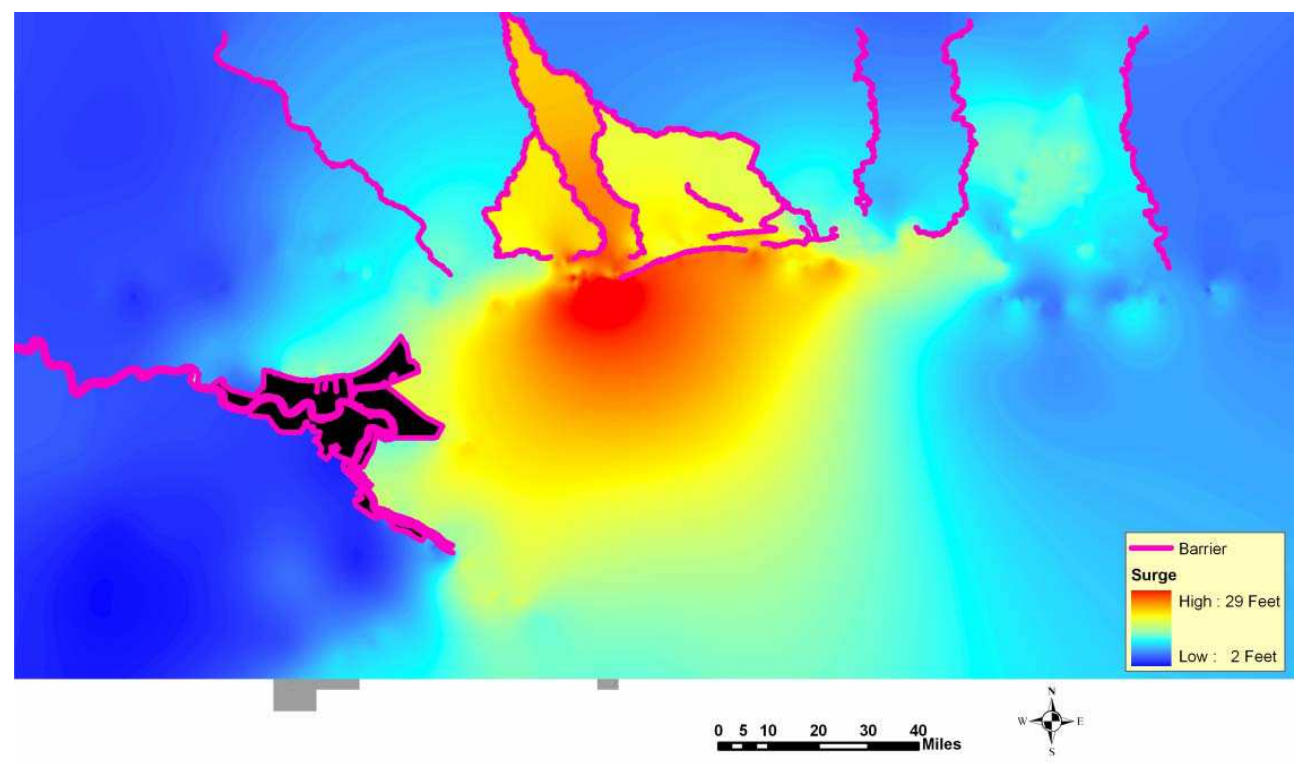

Fig. 1. Improved maximum storm-tide elevation with barriers (from Stoker et al., 2009) 


\subsection{Multi-temporal analyses}

The assessment of a hurricane-impacted forest region and forest damage severity at regional scales has been traditionally based on a ground survey, aerial photography (Gardner et al. 1992), satellite imagery (Kovacs et al. 2001), topographic exposure models (Boose et al. 1994), or simulated by ecological models or storm models. Hurricanes frequently damage and fragment the forested landscape (Boose et al. 1994; Foster and Boose 1992), and Hurricane Katrina was no exception. Large areas of the region were severely damaged, both by the storm surge and by the wind. The spatial patterns of the hurricane's disturbance are essential for managers and scientists to perform efficient management practices such as rebuilding structures, insurance estimations, forest salvage harvesting, habitat protection, as well as to make assessments on long-term environmental impacts and forest ecosystem recovery. Due to the sheer size of areas affected by Katrina, a full-scale ground-based assessment is technically difficult and not very economical (Wang and $\mathrm{Xu}, 2009$ ). As a result, remote sensing methods are the best option for quantifying disturbed areas over large regions, such as Katrina affected areas. Remote sensing techniques using change detection methods in concert with vegetation indices have been shown to be an effective means for high resolution forest disturbance estimations caused by insect defoliation, clearcuts, and forest fires (Ayala-Silva and Twumasi 2004; Coppin and Bauer 1994; Franklin et al. 2000; Hegarat-Mascle et al. 2006; Kwarteng and Chavez 1998; Lyon et al. 1998; Nackaerts et al. 2005; Ramsey et al. 1997). Change detection with remote sensing typically involves the use of two or more multi-temporal aerial or satellite images to estimate two-dimensional spectral changes between time periods. Three-dimensional change detection based on lidar has been used to help quantify structural changes of damaged forests (Dwyer et al., 1999; Wiesmann et al., 2001; Fransson et al., 2002; Boutet and Weishampel, 2003).

Hurricane damage to forests has been mapped via satellite-based remote sensing in a number of studies. Landsat Thematic Mapper (TM) data at 30-m resolution were used by Kovacs (2001) to map disturbance in mangrove forests and by Clark et al. (2006) to map Hurricane Katrina's impacts on pines and hardwoods in the DeSoto National Forest in southern Mississippi. Ramsey et al. (1998) used 1-km Advanced Very High Resolution Radiometer (AVHRR) imagery to map Katrina's impacts to bottomland hardwood and baldcypress/tupelo (Taxodium distichum/Nyssa aquatica) stands in coastal Louisiana. AVHRR imagery was also used by Ayala-Silva and Twumasi (2004) to investigate spatial patterns of damage related to distance away from the path of Hurricane Georges in Puerto Rico. All of these studies found change in the Normalized Difference Vegetation Index (NDVI) to be a useful indicator of forest damage, but none of the lower-resolution studies systematically validated their estimates against reference data.

Wind speed is the variable probably most influential to forest damage. Doyle et al. (1995) found that the severity and spatial extent of hurricane damage declined at greater distances from the storm track, although (Kelly 1993) found damaging winds may extend farther from the center on the eastern side of the track. Ramsey et al. (2001) compared forest damage in Louisiana with modeled wind speeds and found evidence that the severity of damage depended on the duration for which forests are subjected to wind speeds exceeding a certain critical threshold. Jacobs (2006) used relationships between maximum sustained wind speed and forest damage to create rapid assessment maps of forest damage resulting from Hurricanes Katrina and Rita.

The topographic slope and aspect associated with a forest stand determine its degree of exposure to peak winds (e.g., McNab et al. 2004). Topography also influences the soil 
conditions available for tree rooting. Damage has been found to be greater in valleys than on ridges and slopes, probably because of poor soil drainage, shallow rooting depths, and lack of root anchorage (Basnet et al. 1992).

Lidar was collected by NOAA after Katrina for the southern portions of Hancock, Harrison and Jackson Counties in Mississippi. This data was flown along the coastline in late September / early October 2005. The availability of lidar point cloud data from before and after Katrina allow for an assessment of forest, structural and topographic change in three dimensions, rather than spectral changes in passive optical imagery. By understanding the vertical errors associated with the pre- and post Katrina lidar data, we can evaluate three-dimensional changes outside of the error of the instruments to determine if these differences are indeed true changes, such as destroyed trees, houses and roads or are simply artifacts of the data.

To evaluate three-dimensional changes due to Hurricane Katrina, we created raster images or grids interpolated from the lidar point clouds of these three counties for the bare earth points and the first reflective surface points. Differencing these raster images provided us with an image we have coined the height above ground (HAG) raster, which includes the heights of both vegetation and structures above the bare ground. Employing these techniques for both the pre- and post-Katrina lidar at 3 meters, we were then able to difference the post-Katrina lidar from the pre-Katrina lidar for first reflective surfaces, bare earth surfaces, and the height above ground surfaces. Any negative values indicate a loss in elevation after Katrina (such as from destruction), and any positive elevations indicate increases in elevation (such as from new construction or tree growth). Because of the vertical errors stated in the analysis of the instrumentation used in the projects (18.5 - $40 \mathrm{~cm}$ RMSE) any vertical changes within +/- $56.6 \mathrm{~cm}$ (Root Sum of Squares +/- $40 \mathrm{~cm}$ ) cannot be statistically proven as true change; however, any vertical changes outside of these error bounds need to be looked at more closely as possible bare earth, first reflective surface or HAG changes.

\section{Results}

\subsection{Lidar elevation model results}

After the data were seamlessly integrated, a shaded relief image was created and used for quality assurance and quality control of the processing methods. Initial quality assurance checks revealed that a few tiles needed to be reprocessed, and some differences in the Geoid models used by the disparate projects were detected and corrected. In the final datasets, all elevations are in feet above NAVD88 (Fig. 2).

\subsection{Storm surge results}

The final output of the storm surge model incorporating HWMs and barriers to flow are depicted in Figure 3. The created map is only as accurate and precise as the data used to create it, and for the storm surge analysis used to create the maximum storm surge digital elevation coverage for Hurricane Katrina, the accuracy and precision is no better than the HWMs used to make that coverage. Datasets constructed from field data collected by the USGS, FEMA, USACE, and other scientists and engineers post-Katrina accomplished a significant hindcast of the Katrina devastation that will be used extensively in the future in the rebuilding and redevelopment phases of the north Gulf of Mexico coastal region.

As importantly, the development and use of the storm surge analysis techniques and mapping methods in defining the extent of the Hurricane Katrina storm tide inundation 


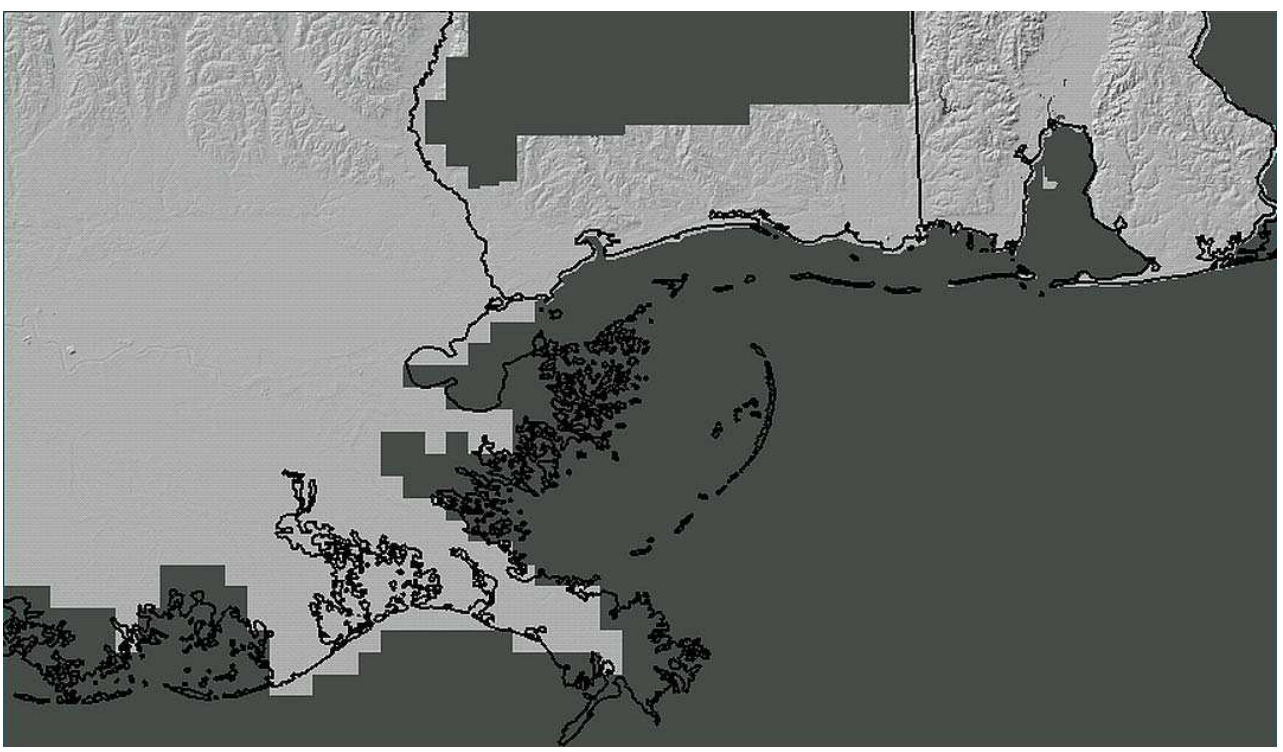

Fig. 2. Final seamless elevation surface from disparate lidar datasets

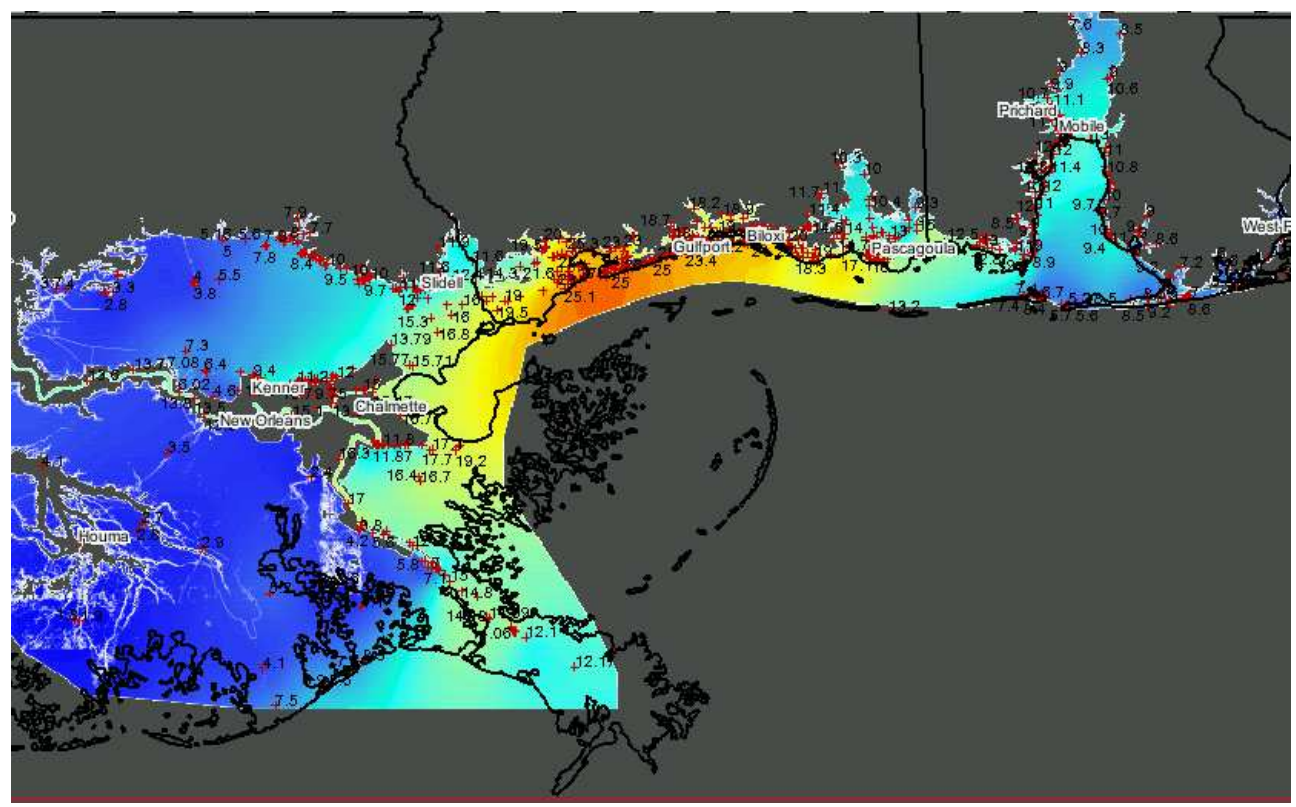

Fig. 3. Final storm surge model incorporating barriers and HWMs

links this critical water-level dataset to the natural topographic and hydraulic features found in southeastern Louisiana, and the Mississippi and Alabama coastlines, and improves the overall depiction of the storm tide for the future of this region. This analysis also provides a 
realistic, consistent, and robust digital map for use by managers and decision makers charged with the recovery of infrastructure in the region. This analysis does not provide the detail or accuracy that could be produced from an appropriately calibrated 2- or 3dimensional hydrodynamic storm surge model, but instead documents a much simpler, but conservative depiction of the extent of flooding represented by the Hurricane Katrina storm tide in Alabama, Mississippi, and southeast Louisiana. Given the need for these critical data before, during, and after such devastating events as Hurricane Katrina, studies such as this may represent the most practical and efficient solution for emergency managers and decision makers that must prepare, warn, and respond to the coastal and inland devastation that intense tropical storms can cause.

\subsection{Multi-temporal results}

After creating the post-Katrina minus pre-Katrina lidar layers, the next task was filtering out the ranges of data that could have been attributed to errors in the two instruments used to collect the lidar. Since the maximum error specified by the vendors for all data was around $+/-40 \mathrm{~cm}$, we assumed that the maximum instrument error between the two temporal datasets was around $2 \mathrm{x}+/-40 \mathrm{~cm}$, or $+/-80 \mathrm{~cm}$. Any vertical differences outside of this 80 $\mathrm{cm}$ range were looked at to determine if these differences were caused by Katrina processes, or were simply other differences or errors in the data.

In parts of coastal Hancock and Harrison Counties, once sensor errors were filtered out, a thin band of changes became quite apparent. To determine the possible cause of this artifact, ancillary data were brought in for comparison. The High Water Marks, post-Katrina imagery, and building footprints digitized in 2007 provided excellent context to the possible nature of this band (Fig 4). The Mississippi Coordinating Council for Remote Sensing and Geographic Information Systems (MCCRSGIS) is part of the Gulf Region Base Mapping Ownership Data Development Project, funded through the Community Development Block Grant (CDBG) program. These vector data were developed for five Coastal Area counties Pearl River, Stone, Hancock, Harrison, and Jackson. The spring 2007 natural color digital orthophotos at 6 inch and 1 foot resolution were used in creation of the data for the project area. Urban areas and the coastline were typically 6 inch resolution with the remaining areas at 1 foot.

Putting this bare earth change layer in context with the high water marks, post-Katrina imagery and 2007 digitized building footprints strongly suggest that the differences in bare earth change along this band relates to debris that was pushed inland due to storm surge. Further analyses of this data needs to be performed before a definitive statement can be made; however, qualitative visual inspection of this artefact strongly suggests this conclusion.

In addition to the bare earth change evaluation, we also compared the height above ground models from before Katrina to after Katrina. After a quick assessment of results, several issues became apparent. Comparing results from the changes in the vertical to various optical change detection methods in the same area highlight the importance of temporal consistency in using lidar for detecting and monitoring non-bare earth vertical change over time (Fig. 5). One of the primary challenges to detect large-scale abrupt vegetation modification is to eliminate or reduce errors caused by vegetation phenology. Due to the fact that this change detection assessment was opportunistic in nature, differences in 
phenology for data collected in early spring/late winter of 2004 for Harrison County, the early spring of 2005 for Hancock and Jackson Counties, and the fall of 2005 after Katrina are apparent. It appears that for the Hancock/Jackson Counties data, there were decreases in the Height Above Ground models, while for northern Harrison County data, there were actually increases in heights. The primary cause of this is believed to be the leaf on/leaf off status of the data due to the differences in dates for each of the collections, and the differences in heights due to high scan angles.

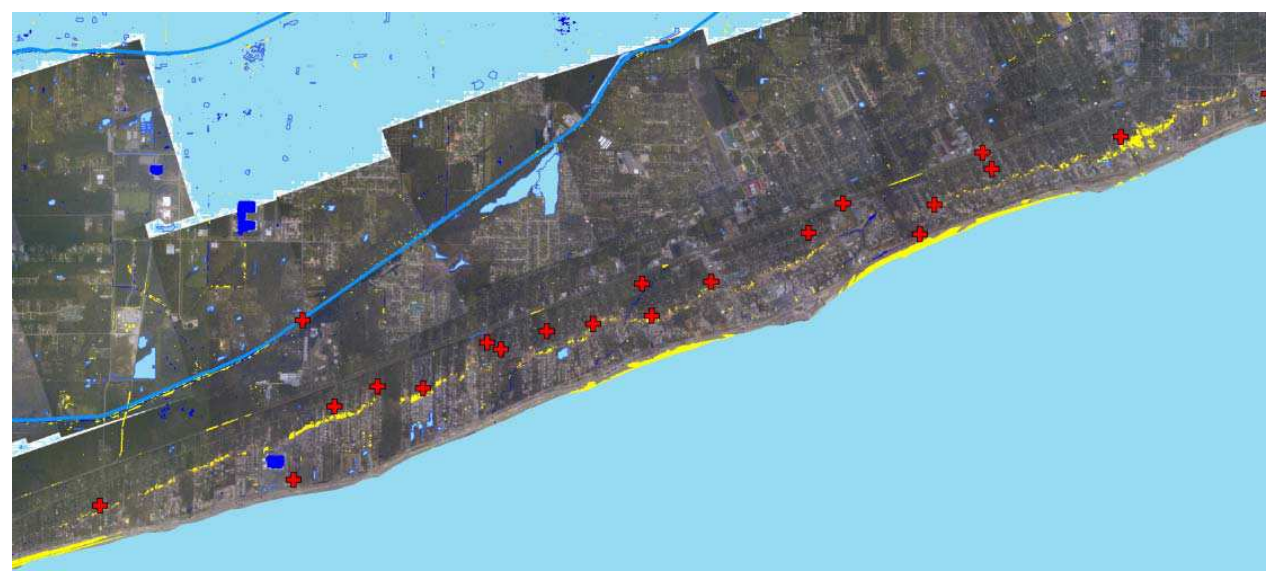

(a)

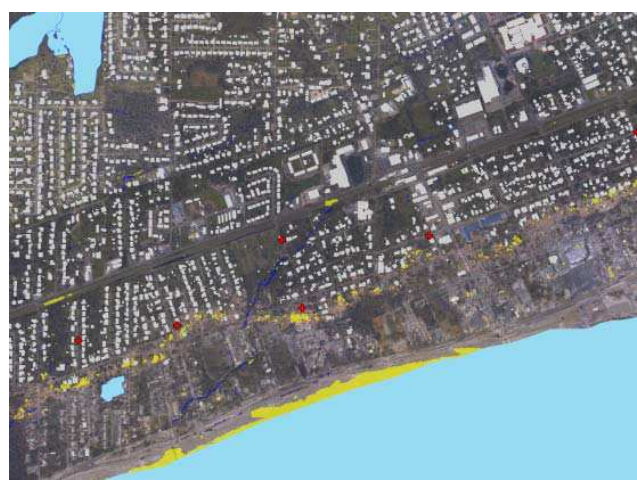

(b)

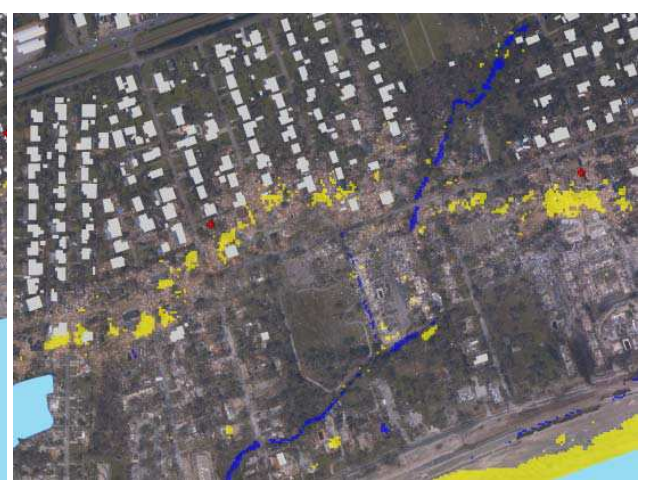

(c)

Fig. 4a, 4b, 4c. Outside-sensor-error vertical changes (yellow $=$ increase, blue $=$ decrease) for bare earth versus HWMs (red crosses) and 2006 MCCRSGIS digitized building footprints 

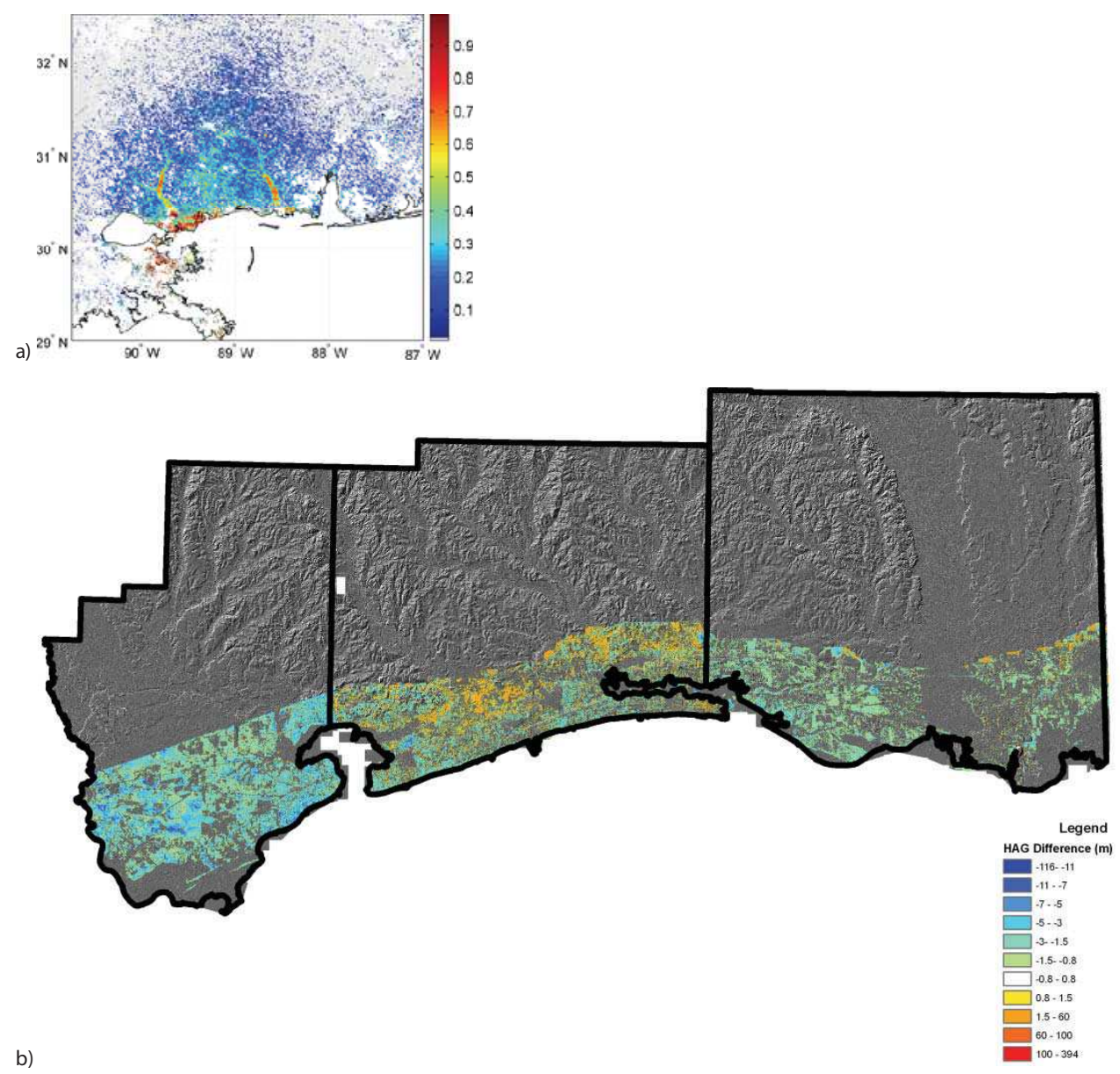

Fig. 5. a) Maps of forest damage levels mapped by Wang et al., 2010, and b) A HAG difference grid from lidar (blue $=$ decrease, red $=$ increase)

For buildings, qualitative comparison demonstrated that the differences in heights related well to the 2007 building footprints (Fig. 6). Areas that show no changes in vertical height correlate well with outlines of building footprints that were digitized in 2007. Areas along the nearshore coastline that show a rectangular pattern of decrease are not digitized as buildings in the 2007 footprint layer. These areas are assumed to be buildings that have been destroyed between the two datasets. There are also areas where digitized polygons are associated with rectangular increases in elevation inside that polygon. These areas are assumed to be buildings that were built between the times of the pre- and post-Katrina datasets. 


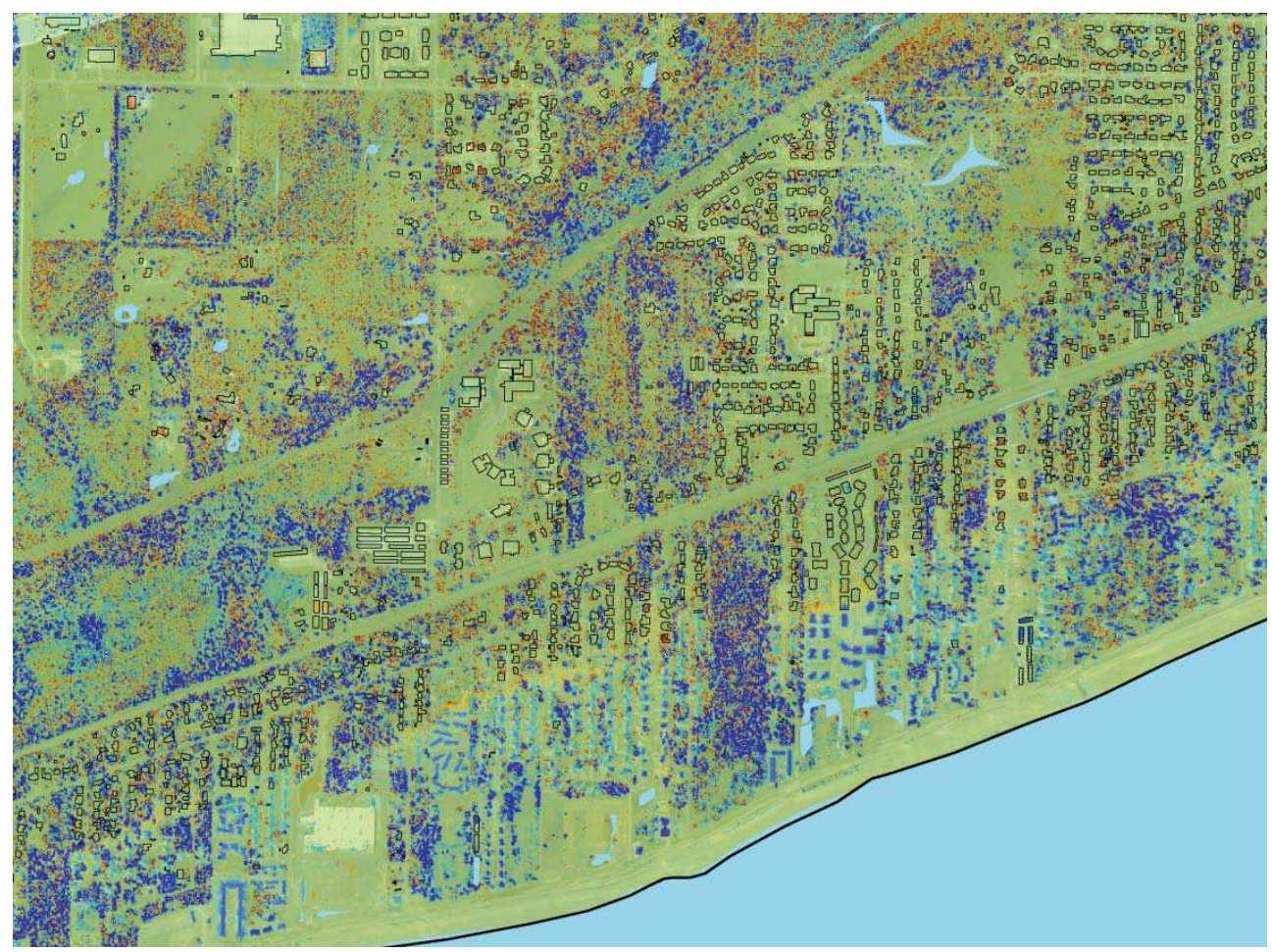

Fig. 6. HAG difference overlaid with 2007 building footprints (red $=$ increase, green $=$ no change, blue $=$ decrease)

Due to the lack of temporal consistency in the pre-and post Katrina datasets, quantifying the amount of vegetation that was affected by Katrina is very difficult. Also, the high scan angles may have contributed to the differences in heights in forested areas. Further work needs to be done with multi-temporal lidar datasets to be confident in our assesments of detecting vertical changes over time. For future monitoring efforts, we would want to actively define consistent specifications in order to minimize the contributions of variability in the pre- and post-event data.

\section{Conclusion}

Hurricane Katrina was one of the largest natural disasters in U.S. history. Due to the sheer size of the affected areas, an unprecedented regional analysis at very high resolution and accuracy was needed to properly quantify and understand the effects of the hurricane and the storm tide. Many disparate sources of lidar data were acquired and processed for varying environmental reasons by pre- and post-Katrina projects. The datasets were in several formats and projections and were processed to varying phases of completion, and as a result the task of producing a seamless digital elevation dataset required a high level of coordination, research, and revision. This completed integration allowed for regional-scale storm surge modeling based on very high-resolution elevation information. Taking advantage of lidar flown after Katrina allowed for an assessment of the capability of lidar 
for change detection in the vertical dimension. Many artifacts that were outside of the error bounds attributable to the sensors themselves actually suggested vertical changes related to storm-induced debris, building creation and destruction, and vegetative change. However, further analysis and better controlled pre- and post-event data needs to be done to fully assess the capability of lidar to detect these three-dimensional changes.

\section{References}

Ayala-Silva, T., Twumasi, Y.A. (2004). Hurricane Georges and vegetation change in Puerto Rico using AVHRR satellite data. International Journal of Remote Sensing Vol. 25, No. 9, 1629-1640.

Basnet, K. Likens, G.E. Scatena, F.N. Lugo, A.E. (1992). Hurricane Hugo: damage to a tropical rainforest in Puerto Rico. Journal of Tropical Ecology. Vol. 8:, 47-55.

Berenbrock, C., Mason, R.R. \& Blanchard, S.F. (2009). Mapping Hurricane Rita inland storm tide, Journal of Flood Risk Management, Vol. 2, No. 1, 76-82.

Boose, E.R., Foster, D.R., Fluet, M. (1994). Hurricane impacts to tropical and temperate forest landscapes. Ecological Monographs 64, 369-400.

Boutet Jr., J.C., Weishampel, J.F. (2003). Spatial pattern analysis of pre- and posthurricane forest canopy structure in North Carolina, USA. Landscape Ecology, 18, 553-559.

Clark, J., Finco, M., Schwind, B., Megown, K. (2006). Rapid assessment of forest damage using multi-temporal Landsat TM imagery and high resolution aerial photography. In: 8th Annual Forest Inventory and Analysis Symposium, Monterey, California, October 16-19.

Coppin, P. R., Bauer, M. E. (1994). Processing of multitemporal Landsat TM imagery to optimize extraction of forest cover change features. IEEE Transactions on Geoscience and Remote Sensing, Vol. 32, No. 4, 918-927.

Doyle, T.W. Keeland, B.D. Gorham, L.E. Johnson, D.J. (1995). Structural impact of Hurricane Andrew on the forested wetlands of the Atchafalaya Basin in South Louisiana. Journal of Coastal Research. Vol. 21, 354-364.

Dwyer, E., Pasquali, P., Holecz, F., Arino, O. (1999). Mapping forest damage caused by the 1999 Lothar Storm in Jura (France), using SAR Interferometry. ESA Earth Observation Quarterly. Vol. 65, 28-29.

Farris, G.S. Smith, G.J. Crane, M.P. Demas, C.R. Robbins, L.L., and Lavoie, D.L., eds. (2007). Science and the storms-the USGS response to the hurricanes of 2005: U.S. Geological Survey Circular 1306, 283p.

Foster DR, Boose ER. (1992). Patterns of forest damage resulting from catastrophic wind in central New England, USA. Journal of Ecology. Vol. 80, 79-98.

Franklin, S. E., Moskal, L. M., Lavigne, M. B., \& Pugh, K. (2000). Interpretation and classification of partially harvested forest stands in the Fundy model forest using multitemporal Landsat TM digital data. Canadian Journal of Remote Sensing. Vol. 26, 318-333.

Fransson, J.E., Walter, F., Blennow, K., Gustavsson, A., Ulander, L.M.H. (2002). Detection of storm-damaged forested areas using airborne CARABAS-II VHF SAR image data. IEEE Transactions on Geoscience and Remote Sensing. Vol. 40, No.10, 2170-2175.

Gardner, L.R., Michener, W.K., Williams, T.M., Blood, E.R., Kjerfve, B., Smock, D.J., Lipscomb, L.A., Gresham, C. (1992). Disturbance effects of Hurricane Hugo on a pristine coastal landscape: North Inlet, South Carolina, USA. Netherlands Journal of Sea Research. Vol. 30, 249-263. 
Gesch, D. (2009). Analysis of lidar elevation data for improved identification and delineation of lands vulnerable to sea-level rise. Journal of Coastal Research, SI(53), 49-58.

Gesch, D. Oimoen, M., Greenlee, S., Nelson, C., Steuck, M., and Tyler, D. (2002). The National Elevation Dataset. Photogrammetric Engineering and Remote Sensing. Vol. 68 , No. 1, 5-11.

Hegarat-Mascle, S. L., Seltz, R., Hubert-Moy, L., Corgne, S., \& Stach, N. (2006). Performance of change detection using remotely sensed data and evidential fusion: Comparison of three cases of application. International Journal of Remote Sensing. Vol 27, 3515-3532.

Interagency Performance Evaluation Taskforce (IPET), (2008). Performance evaluation of the New Orleans and southeast Louisiana hurricane protection system: Final report of the Interagency Performance Evaluation Task Force. Vicksburg, Mississippi: U.S. Army Corps of Engineers, 9v. URL: https://ipet.wes.army.mil/

Jacobs, D.M. (2006). Rapid assessment model for determining extent of hurricane damage. Poster presentation at the Forest Health Monitoring Program work group workshop; 2006 January-February; Charleston, SC.

Kelly, J.F. (1993). Hurricane Andrew forest damage assessment. World Resource Review. Vol. 5, 401-408.

Knabb, R.D. Rhome, J.R., and Brown, D.P. (2005). Tropical cyclone report: Hurricane Katrina 2330 August 2005. Miami, Florida: National Oceanic and Atmospheric Administration, National Hurricane Center, $43 \mathrm{p}$.

URL: http://www.nhc.noaa.gov/pdf/TCR-AL122005_Katrina.pdf

Kovacs, J.M. (2001). Mapping disturbances in a mangrove forest using multi-date Landsat TM imagery. Environmental Management. Vol. 27, 763-776.

Kovacs, J.M., Blanco-Correa, M., Flores-Verdugo, F. (2001). A logistic regression modelof hurricane impacts in a mangrove forest of the Mexican Pacific. Journal of Coastal Research. Vol. 17, No. 1, 30-37.

Kwarteng, A. Y., \& Chavez, P. S. (1998). Change detection study of Kuwait City and environs using multi-temporal Landsat Thematic Mapper data. International Journal of Remote Sensing. Vol. 19, 1651-1662.

Lefsky, M.A.,Cohen, W.B., Parker, G.G., and Harding, D.J. (2002). Lidar remote sensing for ecosystem studies. Bioscience. Vol. 52, No. 1, 19-30.

Link, L. E. (2010). The anatomy of a disaster, an overview of hurricane katrina and new orleans. Ocean Engineering. Vol. 37, No. 1, 4-12.

Lyon, J. G., Yuan, D., Lunetta, R. S., \& Elvidge, C. D. (1998). A change detection experiment using vegetation indices. Photogrammetric Engineering and Remote Sensing. Vol. 64, No. 2, 143-150.

Maas, H.G. (2001). The suitability of airborne laser scanner data for automatic 3D object reconstruction. In: Baltsavias, E.P., Gruen, A. and Van Gool, L. (eds.), Automatic Extraction of Man-Made Objects from Aerial and Space Images (III). Ascona, Switzerland: A.A. Balkema Publishers, pp. 291-296.

McNab, W.H. Greenberg, C.H. Berg, E.C. (2004). Landscape distribution and characteristics of large hurricane-related canopy gaps in a southern Appalachian watershed. Forest Ecology and Management. Vol. 196, 435-447.

Nackaerts, K., Vaesen, K., Muys, B., \& Coppin, P. (2005). Comparative performance of a modified change vector analysis in forest change detection. International Journal of Remote Sensing. Vol. 26, 839-852. 
National Oceanic and Atmospheric Administration (NOAA). (2008). Center for Operational Oceanographic Products and Services: What is the difference between storm surge and storm tide? Silver Spring, Maryland: National Oceanic and Atmospheric Administration, National Ocean Service.

URL: http:/ / co-ops.nos.noaa.gov/quicklook_faqs.shtml

Raber, G.T. and Tullis, J.A. (2007). Rapid assessment of storm-surge inundation after Hurricane Katrina utilizing a modified distance interpolation approach. GIScience and Remote Sensing. Vol. 44, No. 3, 220-236.

Ramsey, E.W., Chappell, D.K., Baldwin, D.G. (1997). AVHRR imagery used to identify hurricane damage in a forested wetland of Louisiana. Photogrammetric Engineering and Remote Sensing. Vol. 63, No. 3, 293-297.

Ramsey, E.W. Chappell, D.K. Jacobs, D.M. Sapkota, S.K. Baldwin, D.G. (1998). Resource management of forested wetlands: hurricane impact and recovery mapped by combining Landsat TM and NOAA AVHRR data. Photogrammetric Engineering and Remote Sensing. Vol. 64, No. 7, 733-738.

Ramsey E.W., Hodgson M.E., Sapkota S.K., Laine S.C., Nelson, G.A., Chappell D.K. (2001). Forest impact estimated with NOAA AVHRR and Landsat TM data related to an empirical hurricane wind-field distribution. Remote Sensing of Environment. Vol. 77, No. 3, 279-92.

Stockdon, H. Doran, K.S., and Sallenger, A.H., Jr. (2009). Extraction of lidar-based dune-crest elevations for use in examining the vulnerability of beaches to inundation during hurricanes. Journal of Coastal Research, SI(53), 59-65.

Stoker, J.M., Greenlee, S.K., Gesch, D.B., and Menig, J.C. (2006). CLICK: The new USGS center for lidar information coordination and knowledge. Photogrammetric Engineering and Remote Sensing, Vol. 72, No. 6, 613-616.

Stoker, J.M. Tyler, D.J. Turnipseed, D.P. Van Wilson, K., Jr., and Oimoen, M.J., 2009. Integrating disparate lidar datasets for a regional storm tide inundation analysis of Hurricane Katrina. Journal of Coastal Research, SI(53), 66-72.

Travis, J. (2005). Hurricane Katrina: Scientists' fears come true as hurricane floods New Orleans. Science, Vol. 309, 1656-1659.

Turnipseed, D.P., Wilson, K. V., Stoker, J., and Tyler, D. (2007). Mapping the Hurricane Katrina storm surge crest in Louisiana, Mississippi, and Alabama, Proceedings of the $37^{\text {th }}$ Annual Mississippi Water Resources Conference (April 24-25, 2007), Jackson, MS, 10 p.

Wang, F., Xu, Y. (2009). Hurricane Katrina-induced forest damage in relation to ecological factors at landscape scale. Environmental Monitoring and Assessment. Vol. 156, No. 14, 491-507.

Wang, W., Qu, J.J., Hao, X., Liu, Y., Stanturf, J.A. (2010). Post-hurricane forest damage assessment using satellite remote sensing Agricultural and Forest Meteorology, Vol. 150, No. 1, 122-132.

Wiesmann, A., Wegmuller, U., Honikel, M., Strozzi, T., Werner, C.L. (2001). Potential and methodology of satellite based SAR for hazard mapping. In: Proceedings of Geoscience and Remote Sensing Symposium, IGARSS 2001, Sydney, Australia, July 9-13. 


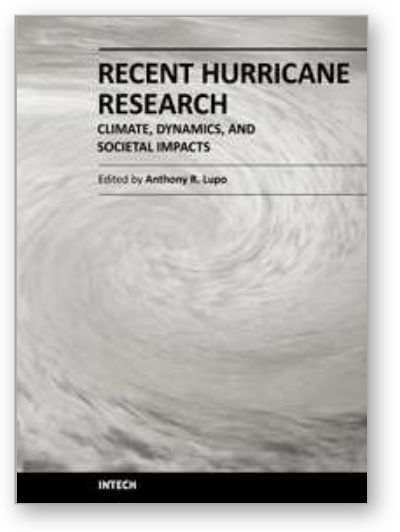

\author{
Recent Hurricane Research - Climate, Dynamics, and Societal \\ Impacts \\ Edited by Prof. Anthony Lupo
}

ISBN 978-953-307-238-8

Hard cover, 616 pages

Publisher InTech

Published online 19, April, 2011

Published in print edition April, 2011

This book represents recent research on tropical cyclones and their impact, and a wide range of topics are covered. An updated global climatology is presented, including the global occurrence of tropical cyclones and the terrestrial factors that may contribute to the variability and long-term trends in their occurrence. Research also examines long term trends in tropical cyclone occurrences and intensity as related to solar activity, while other research discusses the impact climate change may have on these storms. The dynamics and structure of tropical cyclones are studied, with traditional diagnostics employed to examine these as well as more modern approaches in examining their thermodynamics. The book aptly demonstrates how new research into short-range forecasting of tropical cyclone tracks and intensities using satellite information has led to significant improvements. In looking at societal and ecological risks, and damage assessment, authors investigate the use of technology for anticipating, and later evaluating, the amount of damage that is done to human society, watersheds, and forests by land-falling storms. The economic and ecological vulnerability of coastal regions are also studied and are supported by case studies which examine the potential hazards related to the evacuation of populated areas, including medical facilities. These studies provide decision makers with a potential basis for developing improved evacuation techniques.

\title{
How to reference
}

In order to correctly reference this scholarly work, feel free to copy and paste the following:

Jason Stoker, D. Phil Turnipseed and K. Van Wilson (2011). Using Regional-scale Pre- and Post Hurricane Katrina Lidar for Monitoring and Modeling, Recent Hurricane Research - Climate, Dynamics, and Societal Impacts, Prof. Anthony Lupo (Ed.), ISBN: 978-953-307-238-8, InTech, Available from:

http://www.intechopen.com/books/recent-hurricane-research-climate-dynamics-and-societal-impacts/usingregional-scale-pre-and-post-hurricane-katrina-lidar-for-monitoring-and-modeling

\section{INTECH}

open science | open minds

\author{
InTech Europe \\ University Campus STeP Ri \\ Slavka Krautzeka 83/A \\ 51000 Rijeka, Croatia \\ Phone: +385 (51) 770447 \\ Fax: +385 (51) 686166
}

\author{
InTech China \\ Unit 405, Office Block, Hotel Equatorial Shanghai \\ No.65, Yan An Road (West), Shanghai, 200040, China \\ 中国上海市延安西路65号上海国际贵都大饭店办公楼405单元 \\ Phone: +86-21-62489820 \\ Fax: $+86-21-62489821$
}


www.intechopen.com 
(C) 2011 The Author(s). Licensee IntechOpen. This chapter is distributed under the terms of the Creative Commons Attribution-NonCommercialShareAlike-3.0 License, which permits use, distribution and reproduction for non-commercial purposes, provided the original is properly cited and derivative works building on this content are distributed under the same license. 